San Jose State University

From the SelectedWorks of Marjorie R. Freedman

2011

Point-of-Selection Nutrition Information Influences Choice of Portion Size in an All-YouCan-Eat University Dining Hall

Marjorie R. Freedman, San Jose State University 
Point-of-Selection Nutrition Information

\title{
Point-of-Selection Nutrition Information Influences Choice of Portion Size in an All-You-Can-Eat University Dining Hall
}

Marjorie R. Freedman. Journal of Foodservice Business Research, 14:1, 86-98.

\begin{abstract}
There is limited information about point-of-selection nutrition information (POSNI) on food choices in all-you-can-eat university dining halls, where food cost is controlled. This pilot study examined effects of POSNI (pictures of different portion sizes with corresponding nutrition information), on students' choice of French fries (FF) and salad dressing (SD), and portion size of FF. POSNI significantly decreased percentage consuming "large" portions of $F F(p<0.05)$, but had limited effect on $S D$ choice. Surveys indicated $>99 \%$ of respondents $(n=359)$ recalled POSNI; more females used POSNI to determine portion size. Longer studies are needed to support these promising results.
\end{abstract}

Key Words: Point-of-Selection Nutrition Information, University, Food Choices, Portion Size

\section{INTRODUCTION}

Over $65 \%$ of the adult population is overweight or obese (Ogden, Carroll, Curtin, McDowell, Tabak, \& Flegal, 2006). Because consumption of meals away from home is associated with increased body weight (McCrory, Fuss, Hays, Vinken, Greenberg, \& Roberts, 1999; Bowman \& Vinyard, 2004; Kant \& Graubard, 2004; Wootan \& Osborn, 2006), and given findings that few consumers know the caloric content of restaurant meals (Burton, Creyer, Kees, \& Huggins, 2006), interest in requiring point-of-purchase (POP) nutrition information, especially at fast-food restaurants, is gaining momentum (Bassett et al., 2008, Burton et al. 2006, Dumanovsky, Nonas, Huang, Silver, \& Bassett, 2009; Harnack \& French, 2008; Wootan \& Osborn, 2006). Following California's and New York City's lead in requiring POP nutrition information in chain restaurants (California State Senate 2008; New York City Department of Health $\S 81.50,2006)$, federal legislation now requires calorie labeling on chain restaurant menus, menu boards, and drive-through displays (P.L. 111-148: The Patient Protection and Affordable Care Act, 2010). Studies examining efficacy of POP nutrition information in restaurants, however, have shown limited benefit (Bassett et al., 2008), and have yet to prove that consumer knowledge consistently leads to more healthful choices (Dumanovsky et al., 2009; Harnack, French, Oakes, Story, Jeffery, \& Rydell, 2008).

Over $30 \%$ of college students self-report a high body mass index (BMI $\geq 25)$, classifying them as overweight or obese (American College Health Association, 2009). Weight gain, reported to continue from freshman through senior years (Racette, Deusinger, Strube, Highstein, \& Deusinger, 2008), increases the risk for chronic medical conditions (Pi-Sunyer, 1993). Allyou-can-eat buffet-style dining, and access to a wide variety of foods and beverages on campus, may lead to excess caloric intake (Conklin, Lambert, \& Cranage, 2005). Because college students are forming habits that may persist the rest of their lives, provision of POP information in these venues is potentially quite beneficial. Thirteen studies examined efficacy of POP information on college campuses (Aaron, Evans, \& Mela, 1995; Almanza, Mason, Widdows, \& Girard, 1993; Buscher, Martin, \& Crocker, 2001; Chu, Frongillo, Jones, \& Kaye, 2009; Cinciripini, 1984; Conklin, Cranage, \& Lambert, 2005; Davis \& Rogers, 1982; Davis-Chervin, Rogers, \& Clark, 1985; Driskell, Schake, \& Detter, 2008; French, Jeffery, Story, Hannan \& 
Snyder, 1997; Hoerr \& Louden, 1993; Kolodinsky, Green, Michahelles, \& Harvey-Berino, 2008; Larson-Brown, 1978). Three of these studies examined the impact of POP information in vending machines (French et al., 1997; Hoerr \& Louden, 1993; Larson-Brown, 1978), and ten focused on POP information in college cafeterias and restaurants (Aaron et al., 1995; Almanza, et al., 1993; Buscher et al., 2001; Chu et al., 2009; Cinciripini, 1984; Conklin et al., 2005; Davis \& Rogers, 1982; Davis-Chervin et al., 1985; Driskell et al., 2008; Kolodinsky et al., 2008). Methods used to determine impact and to understand students' purchasing decisions included analysis of sales data and foodservice inventory records, observation of students' menu choices at checkout lines, small focus group discussions and questionnaires. As with restaurant studies, no definitive conclusions can de drawn from these studies of college students, primarily due to inconsistent methodologies and poor assessment tools. Further, in both restaurant and university settings, price, convenience, and taste may be more important than nutrition in influencing food choice (Kolodinsky, et al., 2008; O’Dougherty, et al., 2006).

The all-you-can-eat dining hall at San José State University presented an opportunity to examine provision of point-of-service nutrition information (POSNI) in a context that would control for price, convenience and taste. Students living in dormitory housing are required to purchase a meal plan, which provides access to this dining hall. Once inside the facility, students can choose from a wide variety of menu options, and take as much as they want of any item without consideration of cost. Two commonly consumed, energy-dense items (French fries and salad dressing) were chosen as test foods for three reasons: 1) they were available daily at lunch and dinner; 2) they were items that students could self-serve; and 3) if consumed less frequently, or in smaller portions, there could be a significant impact on overall caloric intake in this population, who self-report high rates of overweight and obesity (American College Health Association, 2009). Thus, by covertly observing students' choices, we sought to determine whether provision of POSNI would affect students' food choice behavior. We hypothesized that students exposed to POSNI in this venue would decrease intake of test foods, and that the effect would not be food specific.

\section{METHODS}

\section{Study Design and Participants}

This five-week, quasi-experimental, observational study, approved by the San José State University Institutional Review Board for human subjects, took place in the only all-you-can-eat dining hall located on a large urban metropolitan campus. An ethnically diverse student body attends this university, and there is no ethnic majority. Subjects were a convenience sample of 1,675 students, 18 to 21 years old, who lived in on-campus residential units, had university meal plans, and consumed some or all of their daily meals in this facility.

During week one (baseline), observational data on student self-choice of French fries and salad dressing were collected in the absence of POSNI. For French fries (Lamb Weston CrispyCoat ${ }^{\mathrm{TM}}$ 5/16" Fries/Thin Regular Cut), the same observer covertly stationed behind the serving counter recorded all self-served portions as either "large" or "small," (after counting the number of fries on each plate), for two hours during lunch on Monday, Wednesday and Friday. "Large" portions were defined as $>18$ fries, and "small" portions $\leq 18$ fries. The number 18 was chosen as it approximates the number of French fries in a small sized $(2 \mathrm{oz})$ portion of French fries sold at popular fast food restaurants. For salad dressing (Caesar, ranch, Thousand Island, 
honey mustard, Italian, oil and vinegar, and raspberry vinaigrette), four trained observers (seated within view of the two salad bars) recorded student choice while pretending to study for two hours on Wednesday and Friday. Salad dressing was available in individually labeled self-serve pitchers (http://catering-supplies.hubert.com/salad-dressing-dispenser-set.html).

For the next four weeks (intervention), observational data were collected in the presence of POSNI for two hours during lunch each Monday, Wednesday and Friday. POSNI consisted of $10^{\prime \prime} \times 7.5^{\prime \prime}$ laminated color signs, designed and prepared especially for this study. The signs were placed at eye-level throughout the dining hall, on the glass sneeze-guards at the point of self-service for the two test foods. Similar signs were also placed for two other commonly consumed items (milk and nacho cheese).

Signs for French fries and nacho cheese showed actual photographs of a "large" sized portion next to a "small" sized portion, with corresponding quantitative nutritional information (total calories, fat grams, percent of total calories from fat based on a 2,000 calorie diet) for each portion size. For French fries, the "large" portion contained $\sim 36$ French fries (350 kcals) while the "small" portion had $\sim 18$ French fries $(175 \mathrm{kcals})$. For the two salad dressing signs, one showed a photograph of a mixed-green salad with $2 \mathrm{oz}$ of dressing next to a photograph of a salad with $1 \mathrm{oz}$, and the other sign showed a drawing of the seven different dressings in $2 \mathrm{oz}$ cups, with the most caloric (Caesar) on the left, and the least caloric (raspberry vinaigrette) on the right. The sign for milk showed drawings of four kinds of milk (whole milk, 1\% milk, lowfat chocolate milk and non-fat milk) in 8 oz glasses. All signs contained nutritional information below each drawing corresponding to each portion size. Each sign also had one or two slogans ("Portion Size Matters" and "A Small Change Makes a BIG Difference") above the photograph or drawing in large bolded font. Small laminated signs with these slogans were placed in various locations throughout the dining hall. In addition, the "Portion Distortion" poster (Learning Zone Express, 2007, Owatonna, MN) was placed on easels at the two entrances to the dining hall, where students are required to swipe their ID card for entrance. All signs were left in place for the duration of the study.

One week after the intervention, all POSNI and slogan signs were removed, and students eating lunch in the dining hall were randomly selected to answer a ten-question, multi-part intercept survey. Questions were designed to determine whether posted nutrition signs and slogans were noticed, and, if so, whether respondents used posted information to help make decisions about which and how much of the signed items to choose. As a manipulation check, non-signed food items and bogus slogans were included in the questionnaire. Students who completed surveys were entered into a drawing for a $\$ 10$ gift certificate redeemable at the campus bookstore.

\section{Data Analysis}

Hypothesis testing and examination of confidence intervals were used to examine differences in choice of French fry portion size between periods (http://glass.ed.asu.edu/stats/analysis). The Mann-Whitney U test for non-normally distributed data determined differences in choice of salad dressings between periods. The chi-square test of homogeneity was used to assess differences between categorical variables in the survey. To determine whether students saw any POSNI, we summed responses to survey questions asking whether they saw valid slogans, pictures, or nutritional information, with responses defined as 0 for "did not see any POSNI" and 1 for "saw POSNI". Analyses were conducted using the 
Statistical Package for the Social Sciences version 16.0 for Mac (SPSS, Chicago, IL, 2008). Statistical significance was set at $p<.05$.

\section{RESULTS}

\section{Effect of POSNI on Student Choice and Portion Size}

Census data indicated 756.2 \pm 178.7 students ate in this dining hall from 11:30 a.m. to 1:30 p.m. during the study period, Spring 2007. There was no difference in percentage of students choosing French fries during the baseline and intervention periods (Table 1). Of the 532 students who chose French fries during the baseline period, 60\%, 95\% CI [55, 63], chose the "large" portion size and 40\%, 95\% CI [37, 45], chose the "small" size. Thus, during baseline students chose "large" portions $20 \%$ more often than they chose "small". Students showed a significant bias towards the "large" portion size $(p<0.05)$, choosing this size more than would be predicted if students showed no preference (i.e., choosing each size at $50 \%$ ).

Table 1. Self-serve Patterns of Students Taking French Fries, Baseline vs. Intervention (Mean \pm SD)

\begin{tabular}{lccccc} 
& \multicolumn{2}{c}{ Baseline } & \multicolumn{2}{c}{ Intervention } & \multicolumn{2}{c}{ Significance } \\
Census count $(\mathrm{N})$ & $\mathrm{n}$ & $\%$ & \multicolumn{2}{c}{$762.3 \pm 193.1$} & $\mathrm{NSD}$ \\
& $177.3 \pm 30.5$ & $24.3 \pm 2.2$ & $183.5 \pm 51.6$ & $25.0 \pm 8.0$ & $\mathrm{NSD}$ \\
$\begin{array}{l}\text { Students choosing } \\
\text { French fries }\end{array}$ & $105.0 \pm 7.9$ & $60.0 \pm 7.0$ & $78.9 \pm 20.5$ & $43.3 \pm 3.1$ & $p<.05$ \\
$\begin{array}{l}\text { Students choosing } \\
\text { "large" portions }\end{array}$ & & & & & \\
$\begin{array}{l}\text { Students choosing } \\
\text { "small" portions }\end{array}$ & $72.3 \pm 24.8$ & $40.0 \pm 7.0$ & $104.6 \pm 31.2$ & $56.7 \pm 3.1$ & $p<.05$
\end{tabular}

Note. Census count is the number of students who swiped their ID card to enter the dining hall.

During the intervention period, preferences were reversed, with $43 \%, 95 \%$ CI [41, 45], choosing the "large" size and 57\%, 95\% CI [55, 59], choosing the "small" size. These data show students chose the "large" portion of French Fries significantly less frequently (14\%) than the "small" size, and represents a significant (17\%) reduction in choice of the "large" size from baseline $(p<0.05)$. These results also indicate students' choice for the "large" size was significantly less than would be predicted if students had no preference $(p<0.05)$ (Table 1$)$.

During the intervention period, there was no significant difference in the percentage of students who chose salad dressing (Table 2). The percentage of students choosing Thousand Island and honey mustard dressings, however, significantly increased. There were no other significant changes in choice of salad dressing. 
Table 2. Self-serve Patterns of Students Taking Salad Dressing, Baseline vs. Intervention $($ Mean \pm SD)

\begin{tabular}{|c|c|c|c|c|c|}
\hline & \multicolumn{2}{|c|}{ Baseline } & \multicolumn{2}{|c|}{ Intervention } & Significance \\
\hline Census count $(\mathrm{N})$ & \multicolumn{2}{|c|}{$688.5 \pm 152.0$} & \multicolumn{2}{|c|}{$762.3 \pm 193.1$} & NSD \\
\hline Percent taking dressing & \multicolumn{2}{|c|}{$19.2 \pm 10.8$} & \multicolumn{2}{|c|}{$24.6 \pm 7.1$} & NSD \\
\hline Type of Dressing & $\mathrm{n}$ & $\%$ & $\mathrm{n}$ & $\%$ & \\
\hline Caesar & $8.0 \pm 4.2$ & $5.2 \pm 0.3$ & $2.5 \pm 2.6$ & $1.6 \pm 2.2$ & NSD \\
\hline Ranch & $120.0 \pm 75.0$ & $75.7 \pm 4.1$ & $126.2 \pm 47.8$ & $67.5 \pm 4.2$ & NSD \\
\hline Thousand Island & 0 & 0 & $13.3 \pm 6.6$ & $7.8 \pm 4.1$ & $p<.05$ \\
\hline Honey mustard & $3.0 \pm 0$ & $2.3 \pm 1.3$ & $10.1 \pm 3.4$ & $5.7 \pm 2.0$ & $p<.05$ \\
\hline Italian & $16.0 \pm 9.9$ & $10.1 \pm 0.5$ & $12.9 \pm 8.2$ & $6.5 \pm 2.7$ & NSD \\
\hline Oil and vinegar & $6.5 \pm 2.1$ & $4.5 \pm 1.3$ & $11.5 \pm 3.9$ & $6.4 \pm 1.8$ & NSD \\
\hline Raspberry vinaigrette & $2.5 \pm 0.7$ & $2.1 \pm 1.7$ & $8.0 \pm 3.6$ & $4.3 \pm 1.6$ & NSD \\
\hline Total & $156.0 \pm 90.5$ & 100 & $184.6 \pm 60.7$ & 100 & NSD \\
\hline
\end{tabular}

Note: Salad dressings are listed from greatest to least (calories/oz). Percentages relating to individual salad dressing choice are based on total number of students taking salad dressing in each period.

\section{Results of Intercept Survey}

Of 377 surveys distributed, 17 were discarded due to missing or illogical information, leaving 361 surveys providing information for analysis of the respondents' recognition and use of POSNI. Males completed $53 \%$ of the surveys. At least $86 \%$ of respondents ate lunch or dinner in this dining hall at least three days a week, indicating potentially high exposure to POSNI. When asked: "Have you seen signs in this dining facility displaying nutritional slogans in recent weeks?" over $90 \%(\mathrm{n}=333)$ reported seeing at least one nutritional slogan. The majority of these respondents $(78 \%, n=261)$ reported seeing the slogan "Portion Size Matters," and 65\% (n =217) reported seeing the slogan "A Small Change Makes a BIG Difference". Sixty-seven percent of all survey respondents $(n=243)$ responded affirmatively when asked, "Have you seen signs displaying nutrition information?". Of those that saw signs displaying nutrition information, the most frequently reported response as to type of nutrition information seen was "calories per serving" $(62 \%, \mathrm{n}=151)$ followed by "fat grams" $(47 \%, \mathrm{n}=115)$ and "fat as a percentage of total calories" $(31 \%, \mathrm{n}=75)$. There were no differences between males and females in responses to any of the foregoing questions.

Of all respondents, $47 \%(\mathrm{n}=170)$ reported noticing photographs and pictures comparing different portion sizes. Significantly more females than males used these pictures to estimate the nutrient content (calories, fat) of their French fries, $\chi 2(1, \mathrm{n}=222)=8.63, p=.003$, and salad dressing portions, $\chi^{2}(1, \mathrm{n}=219)=9.74, p=.002$. 
Overall, these data indicate almost all $(n=359)$ respondents recalled seeing some POSNI nutrition information, whether it was a slogan, photograph or drawing, or information about calories and fat, on signs in the dining hall over the course of the intervention.

The survey also asked questions about nine specific foods, four of which were items with POSNI, and five without. When asked, "Did you see posted nutritional information about any of the following foods:" the three highest responses were for foods with POSNI (French fries, salad dressing, and milk; 76\%, 55\% and 49\%, respectively), and the five lowest responses were for foods without POSNI (soda, dessert, chili, fruit, and hot dogs; 31\%, 15\%, 8\%, 8\% and 7\%, respectively). The sign for nacho cheese was seen by $30 \%$ of respondents. The only gender effect was for milk; $20 \%$ more males reported seeing the posted nutritional information, $\chi 2(1, \mathrm{n}$ $=229)=7.36, p=.007$. When asked: "Did seeing nutritional information affect whether or not you chose that food?" $32 \%(n=73)$ of respondents reported that information impacted their choice of French fries, while 24\% $(n=53)$ reported that information impacted their choice of salad dressing. Impact of signs on choice of nacho cheese and milk were lower $(15 \%$ and $16 \%$, respectively). There was no gender effect on reported choice for any food item. When asked, "If you chose the food, did the posted nutrition information change how much of the food you took?" 38\% $(n=84)$ responded in the affirmative for French fries and $26 \%(\mathrm{n}=58)$ for salad dressing. For French fries, $20 \%$ more females responded that the signs influenced the amount they chose, $\chi^{2}(1, \mathrm{n}=223)=5.12, p=.024$, and for salad dressing that percentage rose to $28 \%$, $\chi^{2}(1, \mathrm{n}=221)=5.79, p=.016$.

\section{DISCUSSION}

Other studies have examined the effect of point-of-selection nutrition information in university cafeteria settings (Aaron et al., 1995; Buscher et al., 2001; Cinciripini, 1984; Conklin et al., 2005; Davis \& Rogers, 1982; Davis-Chervin et al., 1985; Driskell et al., 2008; Kolodinsky et al., 2008). This study, however, is the first to quantify the effect of POSNI by covert observation, rather than by relying on sales receipts, inventory records, or surveys. This is important because choice of food, especially in a college setting, may be influenced by cost (Kolodinsky et al., 2008; Levi, Chan, \& Pence, 2006), inventory records may not accurately reflect supply and demand, and surveys are subject to bias and cannot be used to quantify behavioral outcomes. The current study reports that over $99 \%$ of students who ate meals in an all-you-can-eat university dining hall noticed POSNI during the four-week intervention period. It also reports that POSNI significantly affected choice of portion size of French fries, as $17 \%$ of students who self-served a "large" portion prior to POSNI switched to a "small" portion in the presence of POSNI. This study, did not, however, report an overall effect on the percentage of students who chose French fries. Likewise, POSNI did not affect the number of students choosing salad dressing, but did significantly increase the percentage of students choosing Thousand Island and honey mustard, two dressings in the caloric midrange.

These results are intriguing as they suggest POSNI may be effective in influencing portion size and/or choice of some energy-dense foods. For example, with POSNI, students might decrease portion size of French fries, but not stop consumption altogether. Similarly, with POSNI, students may be willing to try a less caloric salad dressing such as Thousand Island or honey mustard, with a similar taste and texture profile as their preferred, more caloric dressing (ranch), but they may be unwilling to switch to the lowest calorie dressing (raspberry vinaigrette) which has completely different hedonistic qualities. Further, ranch dressing is frequently used as 
a dipping sauce for many food items, and it would likely not make sense to students to substitute another dressing for this purpose. These results support the contention that food choices may be made for reasons other than nutrition (Kolodinsky et al., 2008; O'Dougherty et al., 2006). It would be beneficial to examine whether POSNI affects choice of salad dressing when a low-fat ranch dressing, with a comparable taste and texture to its full fat counterpart, is also available.

Methodological differences make it difficult to compare this study to others that have looked at this issue. Preliminary results of this study, however, support earlier findings that nutritional information at POP and point of service is beneficial for college students (Cinciripini, 1984; Conklin et al., 2005a, Buscher et al., 2001; Davis \& Rogers, 1982; Davis-Chervin et al., 1985; Driskell et al., 2008; Kolodinsky et al., 2008). The most effective method of presenting POP nutrition information, however, has not yet been determined. In this study, POSNI was provided both as a visual cue (e.g. photographs and pictures of different sized portions) and as written information (quantitative nutritional information, slogans). Although virtually all respondents noticed POSNI in some form (photograph, picture, slogan or quantitative information), it was not possible to determine whether the visual or the quantitative information had the greatest impact on food choices. It is likely that a combination of visual cues and quantitative information is responsible for the overall impact of POSNI on food choice. Future research might examine which presentation methods or messages best resonate with students, so that POSNI may be tailored for maximal effect.

In contrast to research indicating fewer males compared to females read food labels (Cinciripini, 1984; Cowburn, \& Stockley, 2005; Drichoutis, Lazaridis, \& Nayga 2005; Driskell, et al., 2008; Levi, et al., 2006; Krukowski, Harvey-Berino, Kolodinsky, Narsana, \& DeSisto, 2006), this study did not report any gender differences in recall of POSNI, or on self-reported effects of POSNI on overall food choices. This study did, however, indicate more females reported using POSNI (especially the visual cues) to determine how much food they chose. These results support Krukowski et al.'s (2006) finding that women, more than men, desire more nutrition information, and support Levi et al.'s (2006) contention that women use nutrition information to inform healthful food choices. It is likely that females who chose smaller portions of French fries in this study believed they were making more healthful choices. Because this study failed to observe portion size choice based on gender, it cannot determine whether POSNI's effect was gender specific. Future studies should be conducted to examine potential gender differences.

Notably, this study's survey results did not match covert observations. This point underscores inherent problems with surveys, and casts doubt on studies relying primarily on survey data to determine efficacy of POP nutrition information on food choices. For example, in this study, $32 \%$ of respondents reported that seeing nutritional information had an impact on their choice of French fries, whereas covert observation revealed no change in the percentage of students taking French fries during the intervention. In addition, 38\% of respondents reported that seeing POSNI affected the amount of French fries chosen, while observations revealed 17\% of students chose smaller portion sizes. This discrepancy may be due to differences between survey respondents and those who were observed, and the inability to capture accurate observational data because of limited observations. Since French fries were available daily for both lunch and dinner, but covert observations took place only three days a week during lunch, it is possible that some respondents did, in fact, choose French fries less often than what was observed, or that more respondents chose smaller portion sizes than what was observed, due to behaviors taking place on non-observation days or during dinner. Alternatively, some students 
who reported choosing fewer French fries may have indeed done so, but their choices may still have been classified as "large" portions by the observer. This would be the case if students decreased selection from $>18$ French fries to at least 18. These discrepancies point to the importance of a longer observation period, and the problem of respondent's classification of "large" and "small portions" not matching that of the observer.

\section{Limitations}

This study was limited by its short duration, especially during the baseline period; the lack of control over menu items that may have affected choice of food and amount taken; possible behavioral changes of students due to perception of being observed; potential observer bias; potential errors in judging a portion to be "small" or "large"; and the inability to match students who were observed with respondents who completed surveys. In addition, though not part of the study design, no information was collected regarding possible changes in intake of other foods when portion size of French fries was reduced. Despite these limitations, the instant promising results suggest that longer studies, with enough statistical power to detect significant differences, are warranted.

\section{CONCLUSIONS AND IMPLICATIONS FOR THE FOOD SERVICE INDUSTRY}

This is the first study to report the beneficial effect of POSNI, provided by visual cues (e.g., photographs and pictures) coupled with quantitative nutrition information, on food choices, in any setting. Though preliminary, this study's results indicate that in a college setting, POSNI can help increase students' awareness of the nutritional value of foods offered, and thereby lead to more healthful choices. This is especially important when looking at the types and kinds of foods commonly consumed by young adults, who are already at risk for weight gain during their college years (Racette et al., 2008) and beyond (Mokdad et al., 1999). For example, for students who consume French fries a few times a week, reducing the portion size by even a small amount can add up to significant caloric savings over the course of the school year. Considering the entire student population, potential caloric savings due to labeling strategies could be significant (Simon, Kuo, \& Fielding, 2008).

Future studies should examine the effects of POSNI coupled with nutrition education.

Krukowski et al. (2006) hypothesized that contextual nutrition education may be necessary prior to labeling initiatives, and Hawthorne, Moreland, Griffin and Abrams (2006) reported educational sessions were effective in teaching adolescents aged 11 to 14 years to read the Nutrition Facts label. In the context of limited funding for public health measures, studies are needed to determine the most cost-effective intervention(s). For example, public health decision makers would benefit by knowing whether the most advantageous way to get people to eat more healthfully is nutrition education alone, POSNI alone, nutrition education coupled with POSNI, public health strategies to reduce portion size, or simply lowering the price of healthful foods (French, 2003).

Of particular import to food service managers and public health advocates is that POSNI used in this study was very inexpensive. At a cost of $\$ 1.00$ per sign, managers could easily afford to place signs on self-serve items throughout their facilities. Further, reducing portion size could have a significant impact on food costs and food waste over the course of the school year (Freedman \& Brochardo, 2010).

In summary, the results of this pilot study reveal that POSNI (as a combination of visual and written nutrition information), provided in a university all-you-can-eat dining facility, 
provides benefit with respect to food choices. Longer studies, which examine gender differences, whether the effects of POSNI are food specific, and which methods/messages are most effective in changing behavior, are needed in order to help inform policy aimed at improving the overall health of the population, in general, and college students, in particular.

\section{ACKNOWLEDGEMENTS}

This research was made possible by a HEAL grant from Kaiser Permanente, Northern California. The author would like to thank Julie Smith for data collection, SJSU nutrition students for their help with observations, Sean Laraway for statistical help, and Brian Mitchler and the staff at the Dining Commons for their assistance throughout the study.

\section{REFERENCES}

1. Aron, J., Evans, R. \& Mela, D. (1995). Paradoxical effect of a nutrition labeling scheme in a student cafeteria. Nutrition Research, 15, 1251-1261.

2. Almanza, B. A, Mason, A. C., Widdows, R. \& Girard, F. J. (1993). Consumer responses to nutrition guidelines labeling in a university restaurant. Journal of the American Dietetic Association, 93, 580-581.

3. American College Health Association. (2009). American College Health AssociationNational College Health Assessment Spring 2008 Reference Group Data Report (abridged): The American College Health Association. Journal of American College Health, 57, 477488.

4. Bassett, M. T., Dumanovsky, T., Huang, C., Silver, L. D., Young, C., Nonas, C., Matte, T. D., Chideya, S., \& Frieden, T. R. (2008). Purchasing behavior and calorie information at fastfood chains in New York City. American Journal of Public Health, 98, 1457-1459.

5. Bowman, S. A., \& Vinyard, B. T. (2004). Fast food consumption of US adults: Impact on energy and nutrient intakes and overweight status. Journal of the American College of Nutrition, 23, 163-168.

6. Burton, S., Creyer, E. H., Kees, J., \& Huggins, K. (2006). Attacking the obesity epidemic: The potential health benefits of nutrition information provision in restaurants American Journal of Public Health, 96, 1669-1675.

7. Buscher, L.A., Martin, K.A., \& Crocker, S. (2001). Point-of-purchase messages framed in terms of cost, convenience, taste, and energy improve healthful snack selection in a college foodservice setting. Journal of the American Dietetic Association, 101, 909-913.

8. California State Senate. Senate Bill No. 1420 Available at: http://info.sen.ca.gov/pub/0708/bill/sen/sb_1401-1450/sb_1420_bill_20080930_chaptered.pdf. Accessed July 10, 2009.

9. Chu, Y. H., Frongillo, E. A., Jones, S. J., \& Kaye, G. L. (2009). Improving patrons' meal selections through the use of point-of-selection nutrition labels. American Journal of Public Health, 99, 2001-2005.

10. Cinciripini, P. (1984). Changing food selections in a pubic cafeteria: an applied behavioral analysis. Behavior Modification, 8, 520-539.

11. Conklin, M., Cranage, D., \& Lambert, C. (2005). College students' use of point of selection nutrition information. Topics in Clinical Nutrition, 20, 97-108.

12. Cowburn, G., \& Stockley, L. (2005). Consumer understanding and use of nutrition labelling: a systematic review. Public Health Nutrition, 8, 21-28. 
13. Davis, D., \& Rogers, T. (1982). Point-of-choice nutrition information for the modification of milk selection. Journal of American College Health, 30, 275-278.

14. Davis-Chervin, D., Rogers, T., \& Clark, M. (1985). Influencing food selection with point-ofnutrition information. Journal of Nutrition Education, 17, 18-22.

15. Drichoutis, A.C., Laxaridis, P., \& Nayga, R.M. (2005). Nutrition knowledge and consumer use of nutritional food labels. European Review of Agricultural Economics, 32, 93-118.

16. Driskell, J. A., Schake, M. C., \& Detter, H. A. (2008). Using nutrition labeling as a potential tool for changing eating habits of university dining hall patrons. Journal of the American Dietetic Association, 201, 2071-2076.

17. Dumanovsky, T., Nonas, C. A., Huang, C. Y., Silver, L. D., \& Bassett, M. T. (2009). What people buy from fast-food restaurants: Caloric content and menu item selection, New York City 2007. Obesity, 17, 1369-1374.

18. Freedman, M. R., \& Brochardo, C. (2010). Reducing portion size reduces food intake and plate waste. Obesity 18: 1864-1866.

19. French, S.A. (2003). Pricing effects on food choices. Journal of Nutrition, 133, 841S-843S.

20. French, S. A., Jeffery, R. W., Story, M., Hannan, P. \& Snyder, M. P. (1997). A pricing strategy to promote low-fat snack choices through vending machines. American Journal of Public Health, 87, 849-851.

21. Harnack, L. J., \& French, S. A. (2008). Effect of point-of-purchase calorie labeling on restaurant and cafeteria food choices: A review of the literature. International Journal of Behavioral Nutrition and Physical Activity, 5:51 doi:10.1186/1479-5868-5-51

22. Harnack, L. J., French, S. A., Oakes, J. M., Story, M. T., Jeffery, R. W., \& Rydell, S. A. (2008). Effects of calorie labeling and value size pricing on fast food meal choices: Results from an experimental trial. International Journal of Behavioral Nutrition and Physical Activity, 5, 63. doi:10.1186/1479-5868-5-63

23. Hawthorne, K. M., Moreland, K., Griffin, I. J., \& Abrams, S. A. (2006). An educational program enhances food label understanding of young adolescents. Journal of the American Dietetic Association, 106, 913-916.

24. Hoerr, S. L., \& Louen, V. A. (1993) Can nutrition information increase sales of healthful vended snacks? Journal of School Health, 63, 386-390.

25. Kant, A. K., \& Graubard, B. I. (2004). Eating out in American, 1987-2000: trends and nutritional correlates. Preventive Medicine 38:243-249.

26. Kolodinsky, J., Green, J., Michahelles, M., \& Harvey-Berino, J. R. (2008). The use of nutritional labels by college students in a food-court setting. Journal of American College Health, 57, 297-302.

27. Krukowski, R. A., Harvey-Berino, J., Kolodinsky, J., Narsana, R. T., \& DeSisto, T. P. (2006). Consumers may not use or understand calorie labeling in restaurants. Journal of the American Dietetic Association, 106, 917-920.

28. Larson-Brown, L. (1978). Point-of-purchase information on vended foods. Journal of Nutrition Education, 10, 116-118.

29. Levi, A., Chan, K., \& Pence, D. (2006). Real men do not read labels: the effects of masculinity and involvement on college students' food decisions. Journal of American College Health, 55, 91-98.

30. McCrory, M. A., Fuss, P. J., Hays, N. P., Vinken, A. G., Greenberg, A. S., \& Roberts, S. B. (1999). Overeating in America: association between restaurant food consumption and body fatness in healthy adult men and women ages 19 to 80. Obesity Research, 7; 564-71. 
31. Mokdad A. H., Serdula, M. K., Dietz, W. H., Bowman, B. A., Marks, J. S., \& Koplan, J. P. (1999). The spread of the obesity epidemic in the United States, 1991-1998. Journal of the American Medical Association, 282; 1519-1522.

32. New York City Department of Health and Mental Hygiene Board of Health. (2006) Notice of adoption of an amendment $(\$ 81.50)$ to article 81 of the New York City health code. Available at: http:/www.nyc.gov/html/doh/downloads/pdf/public/notice-adoption-hc-art8150.pdf. Accessed August 1, 2009.

33. O'Dougherty, M., Harnack, L. J., French, S. A., Story, M., Oakes, J. M. \& Jeffery, R. W. (2006). Nutrition labeling and value size pricing at fast food restaurants: A consumer perspective. American Journal of Health Promotion, 20: 247-50.

34. Ogden, C. L., Carroll, M. D., Curtin, L. R., Mcdowell, M. A., Tabak, C. J. \& Flegal, K. M. (2006). Prevalence of overweight and obesity in the United States, 1999-2004. Journal of the American Medical Association, 295, 1549-1555.

35. Pi-Sunyer, F.X. (1993). Medical hazards of obesity. Annals of Internal Medicine, 119, 655660.

36. Racette, S. B, Deusinger, S. S, Strube M. J., Highsgtein, G. R., \& Deusinger, R.H. (2008). Changes in weight and health behaviors from freshman through senior year of college. Journal of Nutrition Education and Behavior, 40, 39-42.

37. Simon P. J., Kuo, T., \& Fielding J. E. (2008). Menu Labeling as a Potential Strategy for Combating the Obesity Epidemic: A Health Impact Assessment. Los Angeles, CA: Los Angeles Department of Health.

38. U.S. Congress. H.R. 3590: The Patient Protection and Affordable Care Act. Available from: http://thomas.loc.gov/. Accessed March 31, 2010.

39. Wootan, M., \& Osborne, M. (2006). Availability of nutrition information from chain restaurants in the United States. American Journal of Preventive Medicine, 30, 266-268. 